\title{
Reliability and Validity of 39-Item Parkinson's Disease Questionnaire and Parkinson's Disease Quality of Life Questionnaire
}

\section{Fiabilidade e Validade do Questionário de Doença de Parkinson-39 e do Questionário de Qualidade de Vida na Doença de Parkinson}

\author{
Joana JESUS-RIBEIRO* $\otimes^{1}$, Elsa VIEIRA*1, Pedro FERREIRA ${ }^{2}$, Cristina JANUÁRIO ${ }^{1,3}$, António FREIRE ${ }^{1,3}$ \\ Acta Med Port 2017 May;30(5):395-401 - https://doi.org/10.20344/amp.8202
}

\section{ABSTRACT}

Introduction: Parkinson's disease has a significant impact in quality of life, which can be assessed with 39-item Parkinson's Disease Questionnaire and Parkinson's Disease Quality of Life Questionnaire. This study aimed to evaluate the reliability and validity of these scales in Portuguese patients.

Material and Methods: Reliability was assessed through internal consistency (Cronbach's alpha) and reproducibility (intraclass correlation coefficient). Regarding construct validity, we performed one-way analysis of variance across different groups according to modified Hoehn and Yahr scale. For criterion validity, we compared both scales with each other and with the Short Form 36-item Health Survey.

Results: In a total of 100 patients with Parkinson's disease, Cronbach's alpha ranged for 39-item Parkinson's Disease Questionnaire between 0.66 - 0.98, and for Parkinson's Disease Quality of Life Questionnaire, between 0.78 - 0.98 . Intraclass correlation coefficient for 39-item Parkinson's Disease Questionnaire ranged between 0.49 - 0.96, and for Parkinson's Disease Quality of Life Questionnaire, ranged between $0.65-0.96$. Both scales showed, in general, capacity to discriminate differences among patients in the different stages of disease. The scales presented moderate to strong magnitude correlations with some Short Form 36-item Health Survey domains. Discussion: Cronbach's alpha coefficients for most domains were satisfactory. Overall, it has been demonstrated good reproducibility, as well as construct and criterion validity.

Conclusion: The Portuguese versions of both scales showed to be valid and reliable.

Keyword: Parkinson Disease; Quality of Life; Surveys and Questionnaires

\section{RESUMO}

Introdução: A doença de Parkinson tem um impacto significativo na qualidade de vida, podendo ser medido através do Questionário de Doença de Parkinson-39 e do Questionário de Qualidade de Vida na Doença de Parkinson. O objectivo deste estudo foi avaliar a fiabilidade e validade destas escalas em doentes portugueses.

Material e Métodos: A fiabilidade foi avaliada através da consistência interna (alfa de Cronbach) e reprodutibilidade (coeficiente de correlação intraclasse). Relativamente à validade de construção, realizou-se uma análise de variância entre diferentes grupos, de acordo com a escala modificada Hoehn and Yahr. Para a validade de critério comparam-se ambas as escalas entre si e com o Short Form 36-item Health Survey.

Resultados: Num total de 100 doentes com doença de Parkinson, o alfa de Cronbach variou para o Questionário de Doença de Parkinson-39 entre 0,66 - 0,98, e para o Questionário de Qualidade de Vida na Doença de Parkinson, entre 0,78 - 0,98. O coeficiente de correlação intraclasse para o Questionário de Doença de Parkinson-39 variou entre 0,49 - 0,96, e para o Questionário de Qualidade de Vida na Doença de Parkinson, variou entre 0,65-0,96. Ambas as escalas demonstraram, em geral, capacidade de discriminação entre doentes em diferentes estadios da doença. As escalas apresentaram correlações de magnitude moderada a forte com alguns domínios do Short Form 36-item Health Survey.

Discussão: Os coeficientes do alfa de Cronbach foram satisfatórios para a maioria dos domínios. No geral, demonstrou-se boa reprodutibilidade, assim como validade de construção e critério.

Conclusão: As versões portuguesas de ambas as escalas demonstraram ser fiáveis e válidas.

Palavras-chave: Doença de Parkinson; Inquéritos e Questionários; Qualidade de Vida

\section{INTRODUCTION}

Parkinson's disease (PD) is a common neurodegenerative disorder with motor impairment and nonmotor manifestations that result in progressive disability with a significant impact on patients' quality of life (QoL). ${ }^{1,2}$

Traditionally, life expectancy was considered one of the key indicators for PD patients' health. However, it has been recognized that this indicator did not provide any information about the quality of the physical, mental, and social domains of life, the overall quality of life, a multidimensional construct including subjective assessments. ${ }^{3,4}$ On the other hand, when we refer to quality of life in the context of health and disease we usually use the term 'health related

\footnotetext{
* Co-first authors.

1. Neurology Department. Centro Hospitalar e Universitário de Coimbra. Coimbra. Portugal.

2. Centre for Health Studies and Research. Faculdade de Economia. Universidade de Coimbra. Coimbra. Portugal.

3. Faculdade de Medicina. Universidade de Coimbra. Coimbra. Portugal.

$\triangle$ Autor correspondente: Joana Jesus-Ribeiro. joanajribeiro@gmail.com

Recebido: 09 de setembro de 2016 - Aceite: 23 de dezembro de 2016 | Copyright @ Ordem dos Médicos 2017
} 
quality of life' (HRQoL) in order to distinguish it from other aspects of quality of life..$^{2,3}$ Indeed, the concept of HRQoL encompasses all the aspects of the overall quality of life that can have consequences on the individual health status, well-being and life satisfaction. ${ }^{5}$

In the past years, the interest in health status instruments in PD has increased, as it can contribute to a better understanding of the disease's mainly affected areas and therapeutic interventions benefit as well as to better clinical decisions. However, to obtain an extensive and reliable picture remains difficult. ${ }^{2,6}$

Several HRQoL generic and specific scales have been used in PD patients. ${ }^{1,6,7}$ Both 39-item Parkinson's Disease Questionnaire (PDQ-39) and Parkinson's Disease Quality of Life questionnaire (PDQL) were classified as recommend for use in PD by The Movement Disorder Society Task Force. ${ }^{1,8,9}$ Since issues of HRQoL became a major concern for patient counselling, several validation studies for these scales have been published. ${ }^{10-15}$ However, despite PDQ39 and PDQL were frequently used in current clinical practice, these scales were not validated for the particular Portuguese socio-cultural setting, which may have limited the correct interpretation of the scores previously obtained.

Therefore, we focused this paper on the validation process of the Portuguese versions of PDQ-39 and PDQL, evaluating their reliability and validity for use in clinical practice and research among Portuguese PD patients.

\section{MATERIAL AND METHODS Study design}

Psychometric validation study to evaluate reliability and validity of the Portuguese version of PDQ-39 and PDQL measurement instruments..$^{8,9}$

The present study proceeded in two phases. The first phase - cross-cultural adaptation - followed the sequential approach, commonly used in these type of studies, to obtain linguistically equivalent versions of the original PDQ-39 and PDQL. ${ }^{16,17}$ Semantic equivalence was achieved by two independent translations into Portuguese performed by two Portuguese bilingual experts, a consensus version, followed by a final backward translation performed by another translator, native in English and fluent in Portuguese.

The quality analysis of the translations and the first content validity were checked by a clinician review and in a cognitive debriefing panel with 10 patients with PD. After filling the questionnaires, each participant was asked to point out any difficulties in understanding or ambiguities in the translation. Both questionnaires were then tested for acceptability, understandability, ambiguity and redundancy. This stage completed the creation of the Portuguese versions of both PDQ-39 and PDQL.

The second phase of this study examined the reliability and validity tests of the Portuguese versions. Reliability was assessed by evaluating internal consistency and reproducibility. Internal consistency or homogeneity of data of a domain or scale is the extent to which their data define different aspects of the same attribute and was calculated for each domain. ${ }^{18}$ On the other hand, reproducibility (testretest reliability) is the capacity of the instrument, in stable conditions, to reproduce the same results obtained from an initial evaluation ${ }^{18}$ and was performed by applying the PDQ39 and PDQL in two different times (10 to 12 days apart) to a sample of 13 patients not belonging to the initial sample. The following hypothesis was stated: H1 - Both PDQ-39 and PDQL have acceptable reliability.

Construct validity was tested by comparing the measure scores among known group variables. This type of validity verifies the capacity of the instrument to discriminate among subgroups of patients in different clinical states and was determined by comparing the PDQ-39 and PDQL scores among the groups of patients in different phases of the disease. Therefore, the following hypothesis was stated: $\mathrm{H} 2$ - The average scores from PDQ-39 and PDQL are different upon the disease's stages.

Criterion validity determines the amount of association between measures of the same construct, comparing the PDQ-39 and PDQL with each other and to a logically related generic measure instrument. So, the following hypothesis were stated: H3 - When PDQ-39 and PDQL scores are compared to SF-36 scores, similar domains are correlated; and H4 - PDQ-39 and PDQL measure similar quality dimensions.

\section{Participants}

Patients with clinical diagnosis of PD according to the Queen Square Brain Bank UK PDS Brain Bank Criteria for the diagnosis of $\mathrm{PD}^{19}$ were consecutively recruited from the Neurology Department movement disorder outpatient clinic. Before inclusion of patients in this study, Mini Mental State Examination (MMSE) was performed to evaluate their cognitive state. ${ }^{20} \mathrm{~A}$ cognitive deficit, translated by a MMSE of $\leq 15$ if illiterate patient, $\leq 22$ if patient with 1 11 years of education or $\leq 27$ if patient with educational level higher than 11 years, was an exclusion criteria. ${ }^{20}$ Sociodemographics and clinical characteristics including age, gender, education, employment status and disease status according to modified Hoehn and Yahr scale $(\mathrm{mH} \& \mathrm{Y})^{21}$ were assessed. Both PDQ-39 and PDQL were filled by patients on a scheduled visit to the clinic. In case of comorbidities that prevent patient self-assessment, an informal carer assisted the patient in completing the form. For patients with fluctuations, measurements were applied to an 'on' status.

\section{Instruments}

The PDQL is composed of 37 items grouped into four subscales: parkinsonian symptoms (14 items), systemic symptoms (seven items), social function (seven items), and emotional function (nine items). ${ }^{8}$ Item scores range from 1 (always) to 5 (never). A summary index is computed by averaging all scores for each dimension, ranging from 37 to 185, with higher scores reflecting better HRQoL.

The PDQ-39 is composed of 39 items grouped in eight subscales: mobility (10 items), activities of daily living 
(six items), emotional well-being (six items), stigma (four items), social support (three items), cognitions (four items), communication (three items), and bodily discomfort (three items). ${ }^{9}$ Each item ranges from 0 (never) to 4 (always). Subscale scores and a summary index representing the global HRQoL may also be calculated (0-100), with higher scores representing worse HRQoL.

The Short Form 36-item Health Survey (SF-36) with 36 items is a generic measure of health status leading to eight major health dimensions (physical function, role limitations due to physical or emotional problems, intensity and the discomfort caused by pain, general health, vitality, social function and mental health), all of them on a scale of 0 100 , with the extreme anchors corresponding, respectively, to death and perfect health status. ${ }^{22}$ In this study, the Portuguese version of the SF-36 was used. ${ }^{23,24}$

\section{Statistical analysis}

Descriptive statistics were applied to demographic, rating scales and questionnaire data. Internal consistency reliability was tested by computing the Cronbach's alpha indicator. Scores between 0.70 and 0.95 are considered as acceptable realibility indicators. ${ }^{25}$ The test-retest reliability was tested by the intraclass correlation coefficient (ICC), formula 2.1. A ICC greater or equal to 0.70 was considered positive. ${ }^{25}$

Construct validity was tested by comparing the measured scores (one-way ANOVA with Scheffe post-hoc for pairwise comparisons) among known group variables as well as by the Pearson correlation coefficient $(r)$. The different stages of the disease, according to $\mathrm{mH} \& \mathrm{Y}$ score, were initial $(0.0$ - 1.5), moderate (2.0 - 3.0), and advanced (4.0 - 5.0). The correlation coefficient was interpreted as following: very strong correlation if greater than 0.90 , strong if $0.70<r \leq$ 0.90 , moderate if $0.50<r \leq 0.70$, weak if $0.30<r \leq 0.50$ and very weak or insignificant if less than or equal to $0.30 .{ }^{25} \mathrm{PDQ}$ 39 and PDQL's criteria validity was tested by comparing with each other and with the corresponding scores produced by SF-36. Pearson's correlation coefficients were computed following the same criteria as above. A p value less than 0.05 indicated statistical significance.
Table 1 - Socio-demographic and clinical variables $(n=100)$

\begin{tabular}{lll}
\hline Variable & & \\
\hline Gender & Female & $58.0 \%$ \\
Age & Male & $42.0 \%$ \\
& $\leq 64$ years & $43.0 \%$ \\
& $65-74$ years & $36.0 \%$ \\
& $\geq 75$ years & $21.0 \%$ \\
& Min - Max & $44-82$ \\
& Mean \pm s.d. & $65.8 \pm 9.1$ \\
Education & $<4$ years & $45.0 \%$ \\
& $4-6$ years & $40.0 \%$ \\
& $7-9$ years & $5.0 \%$ \\
Employment status & $10-12$ years & $2.0 \%$ \\
MMSE & $>12$ years & $8.0 \%$ \\
& Active & $19.0 \%$ \\
mH\&Y & Non-active & $81.0 \%$ \\
& Min - Max & $19-30$ \\
& Mean \pm s.d. & $24.9 \pm 3.6$ \\
& Initial stage & $12.0 \%$ \\
& Moderate stage & $77.0 \%$ \\
& Advanced stage & $11.0 \%$ \\
& Min - Max & $1.0-4.0$ \\
& Median & 2.0 \\
& Interquartil range & 1.0 \\
\hline
\end{tabular}

s.d.: Standard deviation; Min: Minimum value; Max: Maximum value; MMSE: Mini Mental State Examination; mH\&Y: Modified Hoehn and Yahr scale

\section{Ethics}

Information about the research was given to all participants who were asked to sign a written informed consent for study participation. The study protocol and ethics procedures were approved by the Ethical Board of our institution.

\section{RESULTS}

\section{Sample}

From a total of 100 PD patients, 58\% were female and the mean age was $65.8( \pm 9.1)$ years. The mean score of MMSE was $24.9( \pm 3.6)$ and the median score of $\mathrm{mH} \& \mathrm{Y}$ was 2.0 (interquartile range 1.0). Table 1 shows the main characteristics of the sample.

Analyzing the global scores for the eight domains of the PDQ-39, mobility and emotional well-being were the more affected areas. In PDQL, systemic symptoms was the more

Table 2 - Mean values and confidence intervals for PDQ-39 and PDQL

\begin{tabular}{|c|c|c|c|c|c|c|}
\hline \multicolumn{2}{|c|}{ Measurement Instrument } & \multirow{2}{*}{$\begin{array}{l}\text { Min - Max } \\
0.0-100.0\end{array}$} & \multirow{2}{*}{$\begin{array}{c}\text { Mean } \pm \text { s.d. } \\
56.5 \pm 27.7\end{array}$} & \multirow{2}{*}{$\begin{array}{c}95 \% \mathrm{Cl} \\
51.0-62.0\end{array}$} & \multirow{2}{*}{$\begin{array}{c}\text { Cronbach's } \alpha \\
0.951\end{array}$} & \multirow{2}{*}{$\begin{array}{l}\text { ICC } \\
0.907\end{array}$} \\
\hline PDQ-39 & Mobility & & & & & \\
\hline & Activities of daily living & $0.0-100.0$ & $47.5 \pm 30.6$ & $41.4-53.6$ & 0.976 & 0.953 \\
\hline & Emotional well-being & $0.0-100.0$ & $51.2 \pm 24.0$ & $46.4-56.0$ & 0.872 & 0.774 \\
\hline & Stigma & $0.0-100.0$ & $30.0 \pm 26.4$ & $24.8-35.2$ & 0.669 & 0.502 \\
\hline & Social support & $0.0-83.3$ & $7.1 \pm 14.7$ & $4.0-10.3$ & 0.981 & 0.964 \\
\hline & Cognitions & $0.0-81.3$ & $39.4 \pm 22.5$ & $35.0-43.9$ & 0.943 & 0.892 \\
\hline & Communication & $0.0-75.0$ & $28.1 \pm 22.3$ & $23.7-32.5$ & 0.947 & 0.899 \\
\hline & Bodily discomfort & $0.0-91.7$ & $48.4 \pm 21.2$ & $44.2-52.6$ & 0.657 & 0.489 \\
\hline \multirow[t]{5}{*}{ PDQL } & Total PDQL & $8.1-100.0$ & $51.7 \pm 18.4$ & $48.0-55.4$ & 0.975 & 0.952 \\
\hline & Parkinsonian symptoms & $8.9-100.0$ & $52.1 \pm 20.4$ & $48.1-56.2$ & 0.978 & 0.957 \\
\hline & Systemic symptoms & $3.6-100.0$ & $47.5 \pm 19.8$ & $43.6-51.5$ & 0.973 & 0.948 \\
\hline & Emotional function & $11.1-100.0$ & $52.2 \pm 17.6$ & $48.7-55.7$ & 0.784 & 0.645 \\
\hline & Social function & $0.0-100.0$ & $54.4 \pm 25.0$ & $49.5-59.4$ & 0.974 & 0.950 \\
\hline
\end{tabular}

Min: Minimum value; Max: Maximum value; s.d.: Standard deviation; $95 \% \mathrm{Cl}$ : 95\% confidence interval; ICC: Intraclass correlation coefficient 
affected domain. Table 2 shows the mean scores and the corresponding standard deviations for the different domains of PDQ-39 and PDQL.

\section{Reliability}

Considering internal consistency, Cronbach's alpha for PDQ-39 ranged from 0.66 (bodily discomfort) to 0.98 (social support). Six dimensions (mobility, activities of daily living, emotional well-being, social support, cognitions and communication) met the standard for an acceptable reliability $(>0.70)$. On the other hand, the other two dimensions showed scores $>0.65$. For the PDQL, Cronbach's alpha ranged from 0.78 (emotional function) to 0.98 (parkinsonian symptoms), all the dimensions exceeding 0.70 .

On the other hand, test-retest scores for PDQ-39 and PDQL yielded statistically significant results. ICC for PDQ39 ranged from 0.49 (bodily disconfort) to 0.96 (social support); stigma and bodily discomfort were not considered positive. Considering PDQL, ICC ranged from 0.65 for emotional function to 0.96 for parkinsonian symptoms. All dimensions, generally, met the standard criteria. Therefore, considering hypothesis $\mathrm{H} 1$, we may say that both measurement instruments are, in general, reliable. Almost all minimum standards were met, and the few exceptions were very close to the minimum standard.

\section{Validity}

Table 3 shows the mean scores for each dimension according to the disease stage and the ANOVA analysis. Last column of this table presents the results of the Scheffe post-hoc test for pairwise comparisons.

To assess the PDQ-39's construct validity, five dimensions (mobility, activities of daily living, cognitions, communication and bodily discomfort) were able to distinguish patients at different $\mathrm{mH} \& \mathrm{Y}$ stages. For the two former dimensions, PDQ-39 was able to distinguish from initial to moderate and from moderate to advanced disease stages (represented in table 3 as $1<2<3$ ); however, the last three dimensions, being able to distinguish between moderate and advanced stages, were not able to distinguish between initial and moderate stages $(1=2<3)$. Also for PDQL, there was a significant difference in QoL scores between groups according to the stage of disease determined by the $\mathrm{mH} \& \mathrm{Y}$. In the total PDQL and in both symptoms dimensions, the scores in initial stage are higher than in moderate stage, and in this stage are also higher than in advanced stage $(1>2>3)$. In the emotional function dimension there is evidence of statistical difference between the initial and the advanced stages but, no strong differences between the two intermediate gaps $(1=2=3)$. Finally, for social function, PDQL was able to distinguish from the initial and the moderate stages but failed to distinguish between moderate and advanced stages $(1>2=3)$. Therefore, taking into account hypothesis $\mathrm{H} 2$, we may state that, in general, both PDQ-39 and PDQL are able to distinguish among the disesase stages defined by $\mathrm{mH} \& \mathrm{Y}$. Major exceptions are the domains emotional well-being, stigma and social support for PDQ-39.

To assess criterion validity we correlated PDQ-39 and PDQL scores with those from a generic health status measurement scale, the SF-36. Table 4 presents the correlation matrix obtained as well as the significance values.

Comparing PDQ-39 and SF-36, we found strong correlations between mobility and physical function, and between emotional well-being and mental health. We also found moderate correlations between activities of daily living and physical function, and between emotional wellbeing and vitality. In what concerns the comparison between PDQL and SF-36, strong correlations were only found between parkinsonian symptoms and physical function. However, moderate correlations were found between parkinsonian symptoms and physical role, vitality and emotional role; between systemic symptoms and physical functioning, physical role, vitality and emotional role; between emotional function and physical role, emotional role and mental health; and between social function and physical functioning, physical role and emotional role. Considering hypothesis $\mathrm{H} 3$, we may defend that although the scales presented moderate to strong magnitude

Table 3 - PDQ-39 and PDQL mean \pm s.d. scores for different severity stages

\begin{tabular}{|c|c|c|c|c|c|c|}
\hline \multicolumn{2}{|c|}{ Measurement Instrument } & \multirow{2}{*}{$\begin{array}{c}\begin{array}{c}\text { Initial stage* } \\
\text { (1) }\end{array} \\
34.2 \pm 26.2\end{array}$} & \multirow{2}{*}{$\begin{array}{c}\text { Moderate stage* } \\
(2)\end{array}$} & \multirow{2}{*}{$\begin{array}{c}\begin{array}{c}\text { Advanced stage* } \\
\text { (3) }\end{array} \\
87.0 \pm 10.5\end{array}$} & \multirow{2}{*}{$\begin{array}{c}\text { Sig } \\
<0.001\end{array}$} & \multirow{2}{*}{$\begin{array}{l}\begin{array}{l}\text { Scheffe } \\
\text { Post-hoc }\end{array} \\
1<2<3\end{array}$} \\
\hline PDQ-39 & Mobility & & & & & \\
\hline & Activities of daily living & $13.5 \pm 15.1$ & $47.7 \pm 27.3$ & $82.9 \pm 24.2$ & $<0.001$ & $1<2<3$ \\
\hline & Emotional well-being & $42.7 \pm 27.5$ & $51.5 \pm 23.6$ & $58.7 \pm 21.8$ & 0.278 & \\
\hline & Stigma & $25.5 \pm 26.8$ & $28.5 \pm 25.0$ & $45.4 \pm 32.6$ & 0.111 & \\
\hline & Social support & $15.6 \pm 19.1$ & $7.0 \pm 14.9$ & 1. $7 \pm 3.5$ & 0.131 & \\
\hline & Cognitions & $28.6 \pm 24.5$ & $38.7 \pm 21.8$ & $56.2 \pm 17.7$ & 0.010 & $1=2<3$ \\
\hline & Communication & $14.6 \pm 21.6$ & $27.2 \pm 21.4$ & $49.2 \pm 14.6$ & $<0.001$ & $1=2<3$ \\
\hline & Bodily discomfort & $40.3 \pm 25.8$ & $47.2 \pm 20.4$ & $65.9 \pm 11.5$ & 0.007 & $1=2<3$ \\
\hline \multirow[t]{5}{*}{ PDQL } & Total PDQL & $68.6 \pm 18.5$ & $51.5 \pm 16.9$ & $35.1 \pm 13.3$ & $<0.001$ & $1>2>3$ \\
\hline & Parkinsonian symptoms & $73.1 \pm 19.3$ & $51.7 \pm 18.5$ & $32.3 \pm 12.4$ & $<0.001$ & $1>2>3$ \\
\hline & Systemic symptoms & $62.8 \pm 20.7$ & $47.9 \pm 18.3$ & $28.6 \pm 13.5$ & $<0.001$ & $1>2>3$ \\
\hline & Emotional function & $61.3 \pm 21.8$ & $52.3 \pm 16.1$ & $41.7 \pm 19.0$ & 0.02 & $1=2=3$ \\
\hline & Social function & $74.7 \pm 18.6$ & $53.5 \pm 24.2$ & $38.6 \pm 24.7$ & 0.03 & $1>2=3$ \\
\hline
\end{tabular}

*mean \pm standard deviation 
Table 4 - Correlations between PDQ-39 and PDQL and SF-36 dimensions

\begin{tabular}{llllllllll}
\hline Measurement Instrument & PF & RP & BP & GH & VT & SF & RE & MH \\
\hline \multirow{2}{*}{ PDQ-39 } & Mobility & -0.77 & -0.56 & -0.39 & -0.37 & -0.45 & -0.30 & -0.45 & -0.33 \\
& Activities of daily living & -0.64 & -0.49 & -0.29 & -0.44 & -0.41 & -0.31 & -0.48 & -0.33 \\
& Emotional well-being & -0.36 & -0.36 & -0.42 & -0.39 & -0.52 & -0.37 & -0.46 & -0.74 \\
& Stigma & -0.38 & -0.32 & -0.23 & -0.44 & -0.31 & -0.30 & -0.39 & -0.43 \\
& Social support & 0.03 & -0.05 & -0.19 & -0.06 & -0.06 & -0.21 & -0.02 & -0.28 \\
& Cognitions & -0.36 & -0.44 & -0.13 & -0.12 & -0.41 & -0.10 & -0.48 & -0.34 \\
& Communication & -0.47 & -0.41 & -0.23 & -0.39 & -0.38 & -0.33 & -0.49 & -0.42 \\
& Bodily discomfort & -0.33 & -0.38 & -0.40 & -0.31 & -0.38 & -0.24 & -0.36 & -0.40 \\
PDQL & & & & & & & & & \\
& Parkinsonian symptoms & 0.70 & 0.61 & 0.38 & 0.40 & 0.50 & 0.32 & 0.54 & 0.38 \\
& Systemic symptoms & 0.57 & 0.63 & 0.49 & 0.40 & 0.59 & 0.37 & 0.56 & 0.48 \\
& Emotional function & 0.37 & 0.54 & 0.38 & 0.45 & 0.48 & 0.36 & 0.59 & 0.57 \\
& Social function & 0.69 & 0.55 & 0.40 & 0.38 & 0.44 & 0.39 & 0.50 & 0.31 \\
\hline
\end{tabular}

PF: Physical functioning; RP: Physical role limitations; BP: Bodily pain; GH: General health; VT: Vitality; SF: Social functioning; RE: Emotional role limitations; MH: Mental health

correlations between similar domains, it becomes clear that they measure different quality of life dimensions in patients with PD.

At last, looking at PDQ-39 and PDQL scores (Table 5), strong correlations were found between PDQ-39's mobility and PDQL's parkinsonian symptoms, social function and emotional function, between PDQ-39's activities of daily living and PDQL's parkinsonian symtoms and emotional function. On the other hand, PDQ-39's social support, communication and bodily discomfort had weak or very weak correlations with all PDQL dimensions. Therefore, referring hypothesis $\mathrm{H} 4$, we may state that $P D Q-39$ and PDQL do not measure the same quality dimensions, despite of showing moderate to strong correlations between their dimensions.

\section{DISCUSSION}

Our results suggest that Portuguese $P D Q-39$ and PDQL, in spite of measuring different aspects of HRQoL, are both reliable and valid instruments. Indeed, Cronbach's alpha coefficients for most domains of PDQ-39 were higher than 0.7 ; the exceptions were stigma and bodily discomfort domains. All the PDQL domains succeded in achieving the standard criteria. The instruments showed good reproducibility, as in general there were no significant variations in the scores obtained from the first and the second application. Once again, the exceptions were stigma and bodily discomfort domains for PDQ-39 and emotional function for PDQL. For the validity evaluation, we observed that the scales had the capacity to discriminate differences in HRQoL among patients in the initial, moderate, and advanced stages of PD in general, excluding the domains emotional well-being, stigma and social support for PDQ-39. Furthermore, correlating the domains of PDQ-39 and PDQL with SF-36, we obtained moderate to strong magnitude correlations between some similar domains of the scales.

Sociodemographic data of the evaluated patients were equivalent to the characteristics observed in other studies of validation of PDQ-39 and PDQL, with similar mean age and disease stage. ${ }^{10,11}$ The internal consistency of the Portuguese PDQ-39 dimensions was in general equivalent to that previously reported and indicative of acceptable reliability. ${ }^{9,11,12}$ Although in previously reported data the internal consistency of the PDQ-39 social support dimension proved to be weak, in our study bodily discomfort appeared as the less consistent dimension. 7,9,11,13,26 Indeed, bodily discomfort has been shown to occasionally possess low internal consistency, which has been partially justified by the small number of items of this dimension and the length of the scale. ${ }^{7,27-29} \mathrm{PDQL}$ proved to have high internal consistency, with Cronbach's alpha coefficient for the majority of the domains slightly higher than those reported elsewhere..$^{8,10,14,30}$ These differences are better attributed to differences in the socio-cultural characteristics of the sample and, perhaps, in the distinct grades of disease's severity. ${ }^{10,14}$ Also, analyzing test-retest for PDQ-39, once again stigma and bodily discomfort did not achieve the standard criteria, suggesting that these dimensions may not provide accurate data. However, in other studies, the social support has been pointed as a weak domain., ${ }^{7,15,31}$ The remaining dimensions scores agreed to those previously reported. ${ }^{12,27}$ Overall PDQL dimensions met the standard

Table 5 - Correlations between PDQ-39 and PDQL dimensions

\begin{tabular}{llccccc}
\hline Measurement Instrument & Total PDQL & PS & SS & EF & SF \\
\hline \multirow{2}{*}{ PDQ-39 } & Mobility & -0.820 & -0.819 & -0.735 & -0.794 & -0.533 \\
& Activities of daily living & -0.773 & -0.790 & -0.674 & -0.712 & -0.527 \\
& Emotional well-being & -0.642 & -0.562 & -0.573 & -0.518 & 0.678 \\
& Stigma & -0.517 & -0.444 & -0.421 & -0.429 & -0.581 \\
& Social support & -0.021 & -0.095 & -0.067 & -0.009 & -0.021 \\
& Cognitions & -0.439 & -0.356 & -0.463 & -0.313 & -0.498 \\
& Communication & -0.690 & -0.685 & -0.617 & -0.577 & -0.558 \\
& Bodily discomfort & -0.469 & -0.432 & -0.528 & -0.363 & -0.377 \\
\hline
\end{tabular}

PS: Parkinsonian symptoms; SS: Systemic symptoms; EF: Emotional function; SF: Social function 
Table 6 - Comparison of reliability data with other studies

\begin{tabular}{|c|c|c|c|c|c|}
\hline Measurement Instrument & & Cronbach's $\alpha$ & & IC & \\
\hline PDQ-39 & Peto et a ${ }^{9}$ & Park et a ${ }^{11}$ & Current study & Martinez-Martin ${ }^{27}$ & Current study \\
\hline Mobility & 0.94 & 0.97 & 0.95 & 0.88 & 0.91 \\
\hline Activities of daily living & 0.89 & 0.96 & 0.98 & 0.81 & 0.95 \\
\hline Emotional well-being & 0.83 & 0.93 & 0.87 & 0.83 & 0.77 \\
\hline Stigma & 0.80 & 0.90 & 0.67 & 0.90 & 0.50 \\
\hline Social support & 0.69 & 0.70 & 0.98 & 0.86 & 0.96 \\
\hline Cognitions & 0.70 & 0.89 & 0.94 & 0.76 & 0.89 \\
\hline Communication & 0.79 & 0.75 & 0.95 & 0.90 & 0.90 \\
\hline Bodily discomfort & 0.75 & 0.78 & 0.66 & 0.83 & 0.49 \\
\hline PDQL & Boer et $a^{\beta}$ & Campos et $a /^{10}$ & Current study & Martinez-Martin ${ }^{27}$ & Current study \\
\hline Parkinsonian symptoms & 0.86 & 0.83 & 0.98 & 0.91 & 0.96 \\
\hline Systemic symptoms & 0.80 & 0.65 & 0.97 & 0.85 & 0.95 \\
\hline Emotional function & 0.82 & 0.79 & 0.78 & 0.81 & 0.65 \\
\hline Social function & 0.87 & 0.80 & 0.97 & 0.88 & 0.95 \\
\hline Total PDQL & 0.94 & 0.93 & 0.98 & - & 0.95 \\
\hline
\end{tabular}

ICC: Intraclass correlation coefficient

reliability criteria with similar results to those of MartinezMartin et al, except for emotional function. ${ }^{27}$ The evaluation of reproducibility performed by Campos et al, using Mann-Whitney test, reported no statistically significant differences between the average scores of the two PDQL applications (Table 6). ${ }^{10}$

In the evaluation of the construct validity of the PDQ39 , most of the dimensions were able to discriminate patients at different $\mathrm{mH} \& \mathrm{Y}$ stages, with scores trending in the right direction, as the majority of the scores increased with $\mathrm{mH} \& Y$ stages. The major exceptions were emotional well-being, stigma and social support, all of them previously reported in other studies as non significant. ${ }^{11,15,31}$ Some authors defended that theses domains were not greatly influenced by disease severity in PD patients. ${ }^{11,32}$ For PDQL all the domains demonstrated significant differences among the stages of the disease. Analysing pairwise comparisons, parkinsonian symptoms and systemic symptoms, had lower scores as the disease advanced, corroborating previously reported data. ${ }^{10,14}$ However, emotional function dimension was not able to distinguish between intermediate stages.

Considering PDQ-39 and SF-36 correlation, it is evident that the instruments address distinct quality of life dimensions in PD patients, in spite of moderate to strong magnitude correlations between similar domains were obtained, corroborating previous published studies. ${ }^{15,31,33}$ PDQL and the established generic measure of health status (SF-36) presented mostly moderate magnitude correlations between similar domains, agreeing with the results presented by Boer et al. ${ }^{8}$

On the other hand, comparing PDQ-39 and PDQL scores we evidence that both instruments deal with some different aspects of HRQoL, although showing moderate to strong correlations between some of their dimensions. Our results are slightly different from those presented by Martinez-Martin et al concerning the magnitude of the correlations and the similarity between dimensions involved, but we have to take in consideration the distinct sample size as well as demographic characteristics (gender, age and disease stage) and that different cut-off values were defined to establish significant magnitude correlations. ${ }^{27}$

Our study has limitations that need to be taken under consideration in its analysis. Firstly, the sample size restricts the extrapolation of the results to other environments. Secondly, the majority of our patients had a moderate stage of the disease, which influence the PDQ-39 results and limit generalizability to other phases of the disease. Furthermore, we have to consider the small sample of patients used in test-retest reliability. However, it is important to consider that test-retest reliability was performed in stable conditions and patients were instructed to document any alteration in their disease state between the two moments of evaluation; significant changes in their disease severity were excluded. Also the time frame used is considered to be small and our results demonstrated, in general, high magnitude values for ICC.

\section{CONCLUSION}

The current study supports the application of the Portuguese versions of PDQ-39 and PDQL in clinical practice and research studies that assess HRQoL in PD patients. Indeed, the majority of our results addressing the reliabity and the validity of these instruments met the standard criteria. Regarding the less positive results, we have to consider the socio-cultural context as well as the language particularities in their interpretation. We recommend the final user to look at the dimensions measured by each instrument in order to decide which one (or both) should implement in their PD patients.

\section{PROTECTION OF HUMANS AND ANIMALS}

Information about the research was given to all 
participants who were asked to sign a written informed consent for study participation. The procedures followed the regulations established by the Helsinki Declaration of the World Medical Association.

\section{DATA CONFIDENTIALITY}

The study protocol and ethics procedures were approved by the Ethical Board of our institution.

\section{REFERENCES}

1. Martinez-Martin P, Jeukens-Visser M, Lyons KE, Rodriguez-Blazquez C, Selai C, Siderowf A, et al. Health-related quality-of-life scales in Parkinson's disease: critique and recommendations. Mov Disord. 2011;26:2371-80.

2. Kuopio AM, Marttila RJ, Helenius H, Toivonen M, Rinne UK. The quality of life in Parkinson's disease. Mov Disord. 2000;15:216-23.

3. The World Health Organization Quality of Life Assessment (WHOQOL): development and general psychometric properties. Soc Sci Med. 1998;46:1569-85.

4. The World Health Organization Quality of Life assessment (WHOQOL): position paper from the World Health Organization. Soc Sci Med. 1995;41:1403-9.

5. McHorney CA. Health status assessment methods for adults: past accomplishments and future challenges. Annu Rev Public Health. 1999;20:309-35.

6. Damiano AM, Snyder C, Strausser B, Willian MK. A review of healthrelated quality-of-life concepts and measures for Parkinson's disease. Qual Life Res. 1999;8:235-43.

7. Marinus J, Ramaker C, van Hilten JJ, Stiggelbout AM. Health related quality of life in Parkinson's disease: a systematic review of disease specific instruments. J Neurol Neurosurg Psychiatry. 2002;72:241-8.

8. de Boer AG, Wijker W, Speelman JD, de Haes JC. Quality of life in patients with Parkinson's disease: development of a questionnaire. J Neurol Neurosurg Psychiatry. 1996;61:70-4.

9. Peto V, Jenkinson C, Fitzpatrick R, Greenhall R. The development and validation of a short measure of functioning and well being for individuals with Parkinson's disease. Qual Life Res. 1995;4:241-8.

10. Campos M, de Rezende $\mathrm{CH}$, Farnese Vda C, da Silva $\mathrm{CH}$, Morales NM, Pinto Rde M. Translation, cross-cultural adaptation, and validation of the Parkinson's disease quality of life questionnaire (PDQL), the "PDQLBR", into Brazilian Portuguese. ISRN Neurol. 2011;2011:954787.

11. Park HJ, Sohng KY, Kim S. Validation of the Korean version of the 39Item Parkinson's disease questionnaire (PDQ-39). Asian Nurs Res. 2014;8:67-74.

12. Katsarou Z, Bostantjopoulou S, Peto V, Alevriadou A, Kiosseoglou G. Quality of life in Parkinson's disease: Greek translation and validation of the Parkinson's disease questionnaire (PDQ-39). Qual Life Res. 2001;10:159-63.

13. Martinez-Martin P, Frades Payo B. Quality of life in Parkinson's disease: validation study of the PDQ-39 Spanish version. The Grupo Centro for Study of Movement Disorders. J Neurol. 1998;245:S34-8.

14. Serrano-Duenas $M$, Martinez-Martin $P$, Vaca-Baquero V. Validation and cross-cultural adjustment of PDQL-questionnaire, Spanish version (Ecuador) (PDQL-EV). Parkinsonism Relat Disord. 2004;10:433-7.

15. Luo W, Gui XH, Wang B, Zhang WY, Ouyang ZY, Guo Y, et al. Validity and reliability testing of the Chinese (mainland) version of the 39-item Parkinson's disease questionnaire (PDQ-39). J Zhejiang Univ Sci B. 2010;11:531-8.

16. Beaton DE, Bombardier C, Guillemin F, Ferraz MB. Guidelines for the process of cross-cultural adaptation of self-report measures. Spine. 2000;25:3186-91.

17. Acquadro $C$, Girourdet $C$, Mear I. Linguistic validation manual for patient-

\section{CONFLICTS OF INTEREST}

All authors report no conflict of interest.

\section{FUNDING SOURCES}

The author and the co-authors of this manuscript report no disclosures or funding.

reported outcomes (PRO) instruments. Lyon: MAPI ResearchTrust; 2004.

18. McHorney CA, Ware JE Jr, Raczek AE. The MOS 36-Item ShortForm Health Survey (SF-36): II. Psychometric and clinical tests of validity in measuring physical and mental health constructs. Med Care. 1993;31:247-63.

19. Berardelli A, Wenning GK, Antonini A, Berg D, Bloem BR, Bonifati V, et al. EFNS/MDS-ES/ENS [corrected] recommendations for the diagnosis of Parkinson's disease. Eur J Neurol. 2013;20:16-34.

20. Folstein MF, Folstein SE, McHugh PR. "Mini-mental state". A practical method for grading the cognitive state of patients for the clinician. J Psychiatr Res. 1975;12:189-98.

21. Hoehn MM, Yahr MD. Parkinsonism: onset, progression and mortality. Neurology. 1967;17:427-42.

22. Ware JE Jr, Sherbourne CD. The MOS 36-item short-form health survey (SF-36). I. Conceptual framework and item selection. Med Care 1992;30:473-83.

23. Ferreira PL. Criação da versão Portuguesa do MOS SF-36. Parte I Adaptação cultural e linguística. Acta Med Port. 2000;13:55-66.

24. Ferreira PL. Criação da versão Portuguesa do MOS SF-36. Parte II Testes de validação. Acta Med Port. 2000;13:119-27.

25. Terwee CB, Bot SD, de Boer MR, van der Windt DA, Knol DL, Dekker $\mathrm{J}$, et al. Quality criteria were proposed for measurement properties of health status questionnaires. J Clin Epidemiol. 2007;60:34-42.

26. Jenkinson C, Peto V, Fitzpatrick R, Greenhall R, Hyman N. Selfreported functioning and well-being in patients with Parkinson's disease: comparison of the short-form health survey (SF-36) and the Parkinson's Disease Questionnaire (PDQ-39). Age Ageing 1995;24:505-9.

27. Martinez-Martin P, Serrano-Duenas M, Forjaz MJ, Serrano MS. Two questionnaires for Parkinson's disease: are the PDQ-39 and PDQL equivalent? Qual Life Res. 2007;16:1221-30.

28. Jenkinson C, Fitzpatrick R, Norquist J, Findley L, Hughes K. Crosscultural evaluation of the Parkinson's Disease Questionnaire: tests of data quality, score reliability, response rate, and scaling assumptions in the United States, Canada, Japan, Italy, and Spain. J Clin Epidemiol. 2003;56:843-7.

29. Hagell P, Whalley D, McKenna SP, Lindvall O. Health status measurement in Parkinson's disease: validity of the PDQ-39 and Nottingham Health Profile. Mov Disord. 2003;18:773-83.

30. Hobson P, Holden A, Meara J. Measuring the impact of Parkinson's disease with the Parkinson's disease quality of life questionnaire. Age Ageing. 1999;28:341-6.

31. Carod-Artal FJ, Martinez-Martin P, Vargas AP. Independent validation of SCOPA-psychosocial and metric properties of the PDQ-39 Brazilian version. Mov Disord. 2007;22:91-8.

32. Fitzpatrick R, Peto V, Jenkinson C, Greenhall R, Hyman N. Healthrelated quality of life in Parkinson's disease: a study of outpatient clinic attenders. Mov Disord. 1997;12:916-22.

33. Martínez Martín P, Frades B, Jiménez Jiménez FJ, Pondal M, López Lozano JJ, Vela L, et al. The PDQ-39 Spanish version: reliability and correlation with the short-form health survey (SF-36). Neurologia. 1999;14:159-63. 